Campos Neutrais - Revista Latino-Americana de Relações Internacionais

Vol. 1, No 2, p. 40-52, Maio - Agosto de 2019

\title{
Conflictos y tensiones del desarrollo eco-territorial en Bolivia
}

Gabriela Lema Icasuriaga ${ }^{1}$

Resumen: A pesar del reconocido "progresismo" del Estado Plurinacional de Bolivia, la reproducción de modelos de desarrollo que no condicen con la identidad social, ni con la biodiversidad, demuestra su incongruencia frente a los conflictos que se manifiestan ante la abertura de una carretera en área indígena de protección ambiental. El territorio indígena Parque Nacional Isiboro Sécure en Bolivia, es uno de los ejemplos más agudos de las estrategias de articulación económica en América Latina. Recientemente el gobierno boliviano suspendió el principio constitucional de mayor protección de la reserva para abertura de una carretera de más de $300 \mathrm{~km}$ de extensión que uniría los municipios de Beni (noreste) y Cochabamba (Centro) con la finalidad de integrar estos pueblos al desarrollo del país y del subcontinente. Nos proponemos realizar una aproximación a la complejidad del caso que articula diversos intereses de movimientos sociales, del gobierno y de geopolítica internacional y articularemos algunos cuestionamientos sobre los límites del concepto de desarrollo socio ambiental.

Palabras clave: américa latina, desarrollo, medio ambiente, progresismos.

\section{Conflicts and tensions of eco-territorial development in Bolivia}

\begin{abstract}
In spite of the recognized "progressivism" of the Plurinational State of Bolivia, the insistence on progress based on development models that do not correspond with social identity or with biodiversity, demonstrates its incongruity in the face of the conflicts that are manifested before the opening of a highway in an indigenous area of environmental protection. The indigenous territory of Isiboro Sécure National Park in Bolivia is one of the most striking examples of economic articulation strategies in Latin America. The Bolivian government recently suspended the constitutional principle of greater protection of the reserve to open a highway of more than $300 \mathrm{~km}$ in length that would link the municipalities of Beni (northeast) and Cochabamba (Center) with the integration of these peoples to the development of the country and the sub-continent. We propose to make an approximation to the complexity of the case that articulates diverse interests of social movements, government and
\end{abstract}


Campos Neutrais - Revista Latino-Americana de Relações Internacionais

Vol. 1, $\mathrm{N}^{\mathrm{O}}$ 2, p. 40-52, Maio - Agosto de 2019

international geopolitics and articulate some questions about the limits of the concept ofsocioenvironmental development.

Keywords: latin america, development, environment, progressisms.

\section{Introducción}

Cuando tomamos como ejemplo la abertura de una carretera que atraviesa el TIPNIS boliviano, lo hacemos pensando en la complejidad que este caso presenta para dilucidar algunos aspectos de la realidad actual de países de América Latina en el contexto regional y mundial. Abordar aspectos del momento presente ya es de por sí un gran desafío, repleto de armadillas que facilitan análisis superficiales sobre la apariencia de los hechos, mientras las dimensiones fundamentales y condicionantes son solapadas en los velos de la historia.

Abandonaremos el inmediatismo para hurgar en aspectos de nuestra historia temprana y desvendar el papel y la función de los usos dados al territorio en nuestra América a partir de su incorporación al sistema mundo capitalista y también la remanencia de formas de apropiación territorial que aún mantienen características ancestrales, anteriores al "choque entre dos mundos"2.

Será a partir de la invasión ibérica que el territorio, que pasará a llamarse América, asume la forma valor de acuerdo con los parámetros y exigencias económicas de las monarquías en crisis. Considerada por los invasores como tierra virgen y sus pobladores como salvajes, la extracción de riquezas y la explotación de la fuerza de trabajo de los nativos llevaron al desarrollo de las ideas fundacionales de la "primera modernidad" y posibilitaron el enriquecimiento de España y Portugal y su entrada al sistema-mundo moderno capitalista (Wallerstein e Quijano, 1992). Justificativas místico religiosas permitieron ejercer la explotación nativa hasta su casi extinción y la extracción de riquezas expandió la monetización de las relaciones comerciales en el resto del mundo. Con la incorporación del nuevo continente los circuitos comerciales se extendieron por el océano Atlántico, encontrando por lo menos otros dos circuitos, el de Tenochtitlán y el de Tawantinsuyo.

Este último, que ocupaba buena parte de la región andina (actualmente una faja territorial que abarca los países de Colombia al sur, Ecuador, Perú, Bolivia y norte de Chile y Argentina) correspondía al Imperio Incaiko, que mismo siendo una organización política análoga a una aristocracia, se fundaba en una economía colectiva y consideraba la tierra y

\footnotetext{
2 "Choque entre dos mundos" fue la denominación atribuida por Adolfo Colombres (1989) a la colonización ibérica en ocasión de las conmemoraciones de los quinientos años de ese hecho histórico. Ni descubrimiento, ni encuentro, sustenta este autor, invasión es el término utilizado por los movimientos indígenas al arribo y saqueo perpetuado por los europeos en estas tierras.
} 
Campos Neutrais - Revista Latino-Americana de Relações Internacionais

Vol. 1, $\mathrm{N}^{\mathrm{O}}$ 2, p. 40-52, Maio - Agosto de 2019

todos los demás recursos naturales como fuentes comunitarias de vida y preservación para todos los habitantes. Mariátegui (2004) llamará esta forma organizativa de "comunismo incaiko", trabajo y usufructo colectivo de la tierra y de sus productos.

Lo que se pone en discusión en este trabajo es un determinado concepto de desarrollo que ha prevalecido en América Latina, a pesar de las enormes resistencias de poblaciones locales y de los avanzos legales y tecnológicos, producto de amplias discusiones y debates en distintas esferas consultivas y deliberativas tanto nacionales, como regionales y mundiales.

La relación entre desarrollo y protección de la naturaleza, sus recursos y productos, ha estado presente en las agendas de todos los encuentros multilaterales de los organismos mundiales desde que la humanidad se deparó con la finitud de los recursos esenciales a la vida. La relación hombre/naturaleza está presente de manera conflictiva desde los albores de la humanidad, como elemento central de la sobrevivencia del hombre en el planeta, pero la toma de conciencia sobre los límites de la explotación desenfrenada de los recursos naturales y de la capacidad limitada del planeta para soportar el aumento exponencial de los desperdicios del modo de vida que adquirió la humanidad, son mucho más recientes.

No nos detendremos en analizar los argumentos de aquellos que aún resisten en entender las urgencias para revertir el modelo de explotación que prevalece hoy en día. Nos interesa traer para el debate una discusión sobre la preservación del hábitat a partir de posiciones que aún se consideran en las trincheras de la defensa de un otro desarrollo. Tomamos como referencia la comprensión de conflicto socioambiental de Svampa (2011) que lo aborda a partir del análisis de las asimetrías de poder entre actores que sustentan intereses y valores divergentes que se manifiestan como contradicciones en las formas de acceso y control de los recursos naturales.

\section{América latina en el nuevo/viejo ciclo de acumulación capitalista}

América Latina y el Caribe han sido históricamente la fuente inagotable de recursos y productos de un modo de producción que se sustenta, desde su génesis, en la explotación desenfrenada de la fuerza de trabajo y en la depredación ilimitada de recursos naturales, inclusive estimulando el avanzo tecnológico para aumentar y acelerar la depredación con vistas a lucros crecientes y acumulación de riquezas concentradas en un número cada vez menor de individuos.

Lo cierto es que toda la región que denominamos Latinoamérica ha estado sometida de forma periférica y subordinada a los diferentes momentos del desarrollo capitalista, lo que significa que a través de diferentes formas de imposición, que van de la violencia directa 
Campos Neutrais - Revista Latino-Americana de Relações Internacionais Vol. 1, $\mathrm{N}^{\mathrm{O}}$ 2, p. 40-52, Maio - Agosto de 2019

ejercida por el poder bélico a la diplomacia de acuerdos internacionales, las enormes riquezas naturales son explotadas en función de necesidades de producción y consumo de los países situados en el centro de poder del capitalismo mundial, así como también ha sido receptáculo de mano de obra excedente, de esos mismos centros, en todos los ciclos de depresión y crisis por los que pasó el capitalismo en sus quinientos años de existencia.

Colonialismo y desarrollo capitalista caminan juntos desde que la historia del "nuevo" continente comenzó a ser escrita y muchas de sus características fundantes permanecen, aunque sus manifestaciones sean más sutiles y encubiertas por el manto del desarrollo que aún domina no solo la explotación material sino también, y quizá de manera más dramática, la construcción de la subjetividad de nuestras sociedades locales. Desarrollo y progreso inscritos en una supuesta línea del tiempo que se distancia de un pasado arcaico y primitivo, son el corolario del concepto de modernidad forjado por sociedades que consiguieron salir de la escasez y la miseria a costas de las riquezas y del sometimiento de otras sociedades, justificando toda su hazaña conquistadora y colonial en un patrón de poder que sustenta su posición jerárquica frente al mundo.

Esta forma específica de racionalidad que avanzará en los siglos siguientes y se tornará mundialmente hegemónica, sobreponiéndose y desconociendo como válidas todas las otras formas de conocimiento y saberes existentes (Quijano, 2005) es fundamental para entender las formas antagónicas de relación, uso y apropiación de la naturaleza entre sectores sociales que, a pesar de haber sido sometidos a los embates del poder colonial y marginalmente incorporados al sistema capitalista hegemónico, continúan defendiendo lo que restó de sus territorios ancestrales convictos por una cosmovisión que no pudo ser extinta a pesar de la persistencia de la colonialidad del poder.

En este sentido sustentamos que la posibilidad de extinguir las resistencias aún presentes en varios países del continente, y no faltan ejemplos que lo demuestren, se hacen más visibles con la incorporación de gobiernos más próximos a las demandas de esos sectores sociales. Dicho de otro modo, la abertura a los diversos gobiernos progresistas que conquistaron el poder con apoyo de sectores sociales hasta el momento relegados de la escena política resultó en un paso más para avanzar en un proyecto de desarrollo que profundiza los lazos de dependencia y subalternidad con los centros del capitalismo mundial.

En el contexto de América Latina, el gobierno de Evo Morales está en sintonía con la asunción de otros gobiernos de la región inscritos en lo que se ha dado a llamar "gobiernos progresistas", que mismo teniendo algunas características comunes difieren en varios aspectos. Uno de los trazos comunes es haber llegado al poder paralelamente a un nuevo ciclo 
Campos Neutrais - Revista Latino-Americana de Relações Internacionais

Vol. 1, $\mathrm{N}^{\mathrm{O}}$ 2, p. 40-52, Maio - Agosto de 2019

de acumulación que renueva la esperanza desarrollista en un cuadro mundial de aumento de los precios de materias primas tan abundantes en estos países. La posibilidad de sortear las crisis económicas mundiales valiéndose de la exportación de productos primarios (commodities) para mantener ciertas ventajas en la balanza de pagamentos, es un elemento presente en la política económica de estos países. Otro elemento común y necesario para comprender mejor el caso en estudio es la creación de tratados y avances de mercados comunes entre los países de la región, entre ellos la Iniciativa para la Integración de la Infraestructura Regional Suramericana (IIRSA), que como su nombre indica busca articular esfuerzos comunes para conectar una ambiciosa red de infraestructura de transporte y comunicaciones en América del Sur y otras obras de gran envergadura como hidroeléctricas y gasoductos ${ }^{3}$.

\section{Autonomía indígena y preservación ambiental en el TIPNIS}

Tomamos el TIPNIS en Bolivia como caso de estudio por considerar este país una de las experiencias más emblemáticas de América Latina en relación con los procesos políticos, sociales y ambientales que se sucedieron en las últimas décadas. Los indígenas, relegados al margen de la sociedad nacional durante siglos, emergen en el escenario boliviano luchando por un proyecto social propio. País de mayoría indígena, Bolivia tiene entre un 60 y $80 \%$ de población descendiente de varias etnias y tradiciones culturales, entre las que predominan los quechuas y aymarás llegando a ser más de $90 \%$ de la población en algunas áreas rurales, pero también muy presentes en áreas urbanas ${ }^{4}$ (Makara, 2013). Desde 1994 la reforma constitucional reconoce el Estado boliviano como plurinacional, con la presencia de naciones subestatales y de la nación estatal, siendo la primera identificada con las diferentes naciones indígenas y la segunda unificadora de toda la población del país (ídem.).

Bolivia entra en los años 2000 atravesada por conflictos y tensiones entre un proyecto oligárquico burgués, que dominaba la escena política y económica del país y un proyecto político popular con gran participación indigenista de múltiples etnias.

Es el movimiento indígena organizado que permite la llegada al gobierno a Evo Morales, de la etnia aymará, que asume su primer mandato a la presidencia del país en 2006

3 El IIRSA prevé un total de 10 ejes de infraestructura de desarrollo para facilitar la circulación de las materias primas que sustentan la economía de estos países, sin dudas un elemento clave para mantener y desarrollar el exitoso modelo productivo. La carretera a través del TIPNIS es una de las piezas clave para componer un corredor de comunicación, correspondiente al eje Perú - Bolivia - Brasil que permitiría, entre otras cosas, redireccionar el flujo de las exportaciones de Brasil por el Océano Pacífico.

$4 \quad$ Se estima la existencia de 36 etnias diferentes en el actual territorio boliviano. 
Campos Neutrais - Revista Latino-Americana de Relações Internacionais Vol. 1, $\mathrm{N}^{\mathrm{O}}$ 2, p. 40-52, Maio - Agosto de 2019

en una disputa tensionada con las fuerzas oligárquico-burguesas. La base social y electoral del nuevo gobierno se asienta en una propuesta de conciliación nacional que contempla tanto las demandas indigenistas y el reconocimiento de sus autonomías, como también en expectativas de fortalecimiento de un Estado centralizador y regulador en torno de un liderazgo personalista (Svampa, 2013, p.2).

Las bases sociales de apoyo que permitieron ganar por amplio margen las dos elecciones encontraron en este líder, indígena y sindical, un baluarte de las tradiciones ancestrales, defensor de la cosmovisión opuesta a la visión eurocéntrica de desarrollo, largamente impuesta para someter ese pueblo. De esa amalgama de intereses y creencias surge un acuerdo plurinacional por la defensa intransigente del medio ambiente y de los recursos naturales, que tiene como principio articulador la preservación de la "Pachamama" o Madre Tierra, como principio y fin de la vida, en contraste con la visión occidental de uso y apropiación de la naturaleza, sometida a los intereses productivos y especulativos de los hombres.

La visión indigenista de la naturaleza, sus recursos y sus productos, es antagónica al sistema de producción imperante, sus recursos y sus productos. Propone una reconstrucción de la organización económica y social que tiene como referencia el pasado incaico, cuya célula productiva era el ayllu, que permaneció como espacio de protección indígena hasta el periodo de la independencia colonial boliviana cuando la elite nacional (criolla) despojó definitivamente el indio de sus tierras: "A lestablecerse la república boliviana, la república de indios fue suprimida legal y formalmente desconociéndose su organización social y política así como sus gobiernos tradicionales" (Mamani, 2013:12).

Por eso el apelo a la reconstrucción del territorio con base en los registros ancestrales ${ }^{5}$ significa para los pueblos indígenas el reconocimiento y el camino para la restauración del ambiente natural y los medios de vida que la tierra proporciona. Los Ayllus entienden que este es el camino para superar las inequidades sociales, económicas, culturales y políticas que sirvieron como base a todos los regímenes de poder colonial.

Mismo después de la promulgación de la Constitución de 2009, que significó un gran avance para el reconocimiento del Estado plurinacional y de una nueva institucionalidad para la consolidación de las entidades territoriales indígenas como garantía de su libre determinación y autogobierno, se hacen más nítidas las contradicciones y dificultades para

5 Las fuentes para recuperar la historia indígena son la oralidad de los viejos y el q'ipi (vulto), um tejido hecho por las mujeres que contiene los títulos de composición y venta de tierras y todos los datos correspondientes al Allú y que es cargado por las autoridades indígenas como símbolo de responsabilidad comunitaria. 
Campos Neutrais - Revista Latino-Americana de Relações Internacionais Vol. 1, $\mathrm{N}^{\mathrm{O}}$ 2, p. 40-52, Maio - Agosto de 2019

hacer efectivos los pactos sociales articulados con la base de sustentación del gobierno.

El conflicto en torno del TIPNIS es ejemplo de esas contradicciones que retomamos en secuencia histórica para comprender las varias dimensiones del caso analizado y la multiplicidad de actores e intereses que lo componen:

Se trata de un área de cerca de 1.236 .296 ha $\left(12.363 \mathrm{~km}^{2}\right)$ localizada en zona de alta diversidad biológica, considera de protección ambiental desde $1965^{6}$ y declarada tierra indígena en 1990 mediante Decreto Supremo 22610, a partir de ese momento se reconoce el área como "Asentamiento Ancestral" de los pueblos Mojeño, Yuracaré, y Chiman, como espacio socioeconómico para su desarrollo ${ }^{7}$. Esta área también alberga una de las mayores reservas de agua dulce de América Latina. Es el hábitat tradicional de pueblos indígenas amazónicos de etnias variadas que viven en condiciones de casi total aislamiento del mundo "civilizado" y extraen lo necesario para su sustento directamente de la naturaleza, son recolectores, pescadores y artesanos.

El Chapare es un distrito del municipio de Cochabamba, que colinda al sur con el territorio del TIPNIS, y que desde los años de 1960 se convirtió en área de colonización de población andina, también de origen indígena, promovida por el gobierno para realojar la mano de obra desempleada de las minas de estaño. Esta colonización aumentó notoriamente hasta los años 80 con el incremento de los plantíos de coca, convertidos en principal producto agrícola como explicaremos con más detalles en el próximo ítem. En la década siguiente, con el mayor control y la criminalización del comercio ilegal hubo disminución del avanzo de la coca y fomento a la diversificación productiva, principalmente con la banana y el palmito, pero también con la madera, provocando áreas de deforestación.

Desde 1997 el TIPNIS es considerado Territorio de Comunidades Originarias y comienzan a realizarse algunos estudios para la regularización de las diferentes regiones y usos del territorio, proceso que da inicio a varios conflictos por la forma de tenencia de la tierra. Para las comunidades originarias la tierra es de uso colectivo y sus reivindicaciones están orientadas a la defensa del ecosistema y sus formas de sobrevivencia. Pero también están los colonos, que reivindican la propiedad con titulación de sus haciendas y defienden la

6 Este decreto estableció los límites del parque: por el norte, los departamentos de La Paz, Beni y Cochabamba, siguiendo por el curso de los ríos Natusama y Sécure hasta la confluencia de este con el Isiboro; por el Sur, por el curso de los ríos Yusama e Isiboro hasta la confluencia con el río Chipiriri; por el Este, de las juntas del río Chipiriri por la cuenca del río Isiboro hasta su unión con el río Sécure junto al puerto General Esteban Arce; por el Oeste, mediante las águas divisórias de ls cordilleras del Sejeruma y Mosetenes.

$7 \quad$ Este Decreto amplió los límites para abracar toda el área externa de los ríos Isiboro y Sécure, incorporando las comunidades allí asentadas y estableció, en su artículo $5^{\circ}$, el trazado de una "línea roja" como límite entre la zona de protección estricta y zonas de usos múltiples. 
Campos Neutrais - Revista Latino-Americana de Relações Internacionais

Vol. 1, No 2, p. 40-52, Maio - Agosto de 2019

diversificación de sus producciones, principalmente los plantíos y comercialización de la coca, a lo que nos referiremos más adelante. Entre indígenas originarios y colonos también existe una gama de intereses, por veces comunes y por otras contradictorios, que hacen más compleja la comprensión del caso en cuestión.

El tema de la tenencia de la tierra se tensiona aún más en 2009, cuando debido a presiones de los colonizadores Evo Morales entrega títulos de demarcación a los pueblos originarios que acaban por reducir la extensión total del TIPNIS en casi 200 mil hectáreas próximas al Chapare.

La construcción de una carretera, que tendría su punto de partida en Villa Tunari, localizada en el Chapare, en la entrada suroeste del TIPNIS, atravesando el territorio indígena hasta San Ignacio de Mojos, ciudad situada al noroeste del parque, perteneciente al municipio de Beni, y geográficamente situada en un entroncamiento de mitad de camino entre la frontera con el estado brasileño de Rondonia y la ciudad capital boliviana, La Paz; comienza a ser trazada en el año de 2008, a partir de acuerdos de financiamiento entre los gobiernos brasileño y boliviano con préstamos del Banco Nacional de Desarrollo de Brasil (BNDS).

No nos detendremos en los detalles del préstamo ni en posibles conjeturas sobre los intereses de ambos países para establecer este acuerdo, aunque nos parece importante resaltar que para su aprobación no hubo exigencias de cumplimiento de los acuerdos internacionales de los que son signatarios ambos países, como el Convenio 169 sobre "protección a los pueblos indígenas y tribales" de la Organización Internacional del Trabajo, que obliga a que se reconozcan los derechos de los pueblos indígenas, en especial la propiedad de sus tierras, los recursos naturales, conocimientos ancestrales, su autodeterminación y la consulta previa en cualquier situación que pueda violar sus derechos.

Problemas con las comunidades originarias y de licencias ambientales atrasaron la construcción de la obra y el gobierno boliviano se vio obligado a substituir parte del equipo técnico gubernamental que no aceptó firmar las licencias ambientales exigidas, lo cual también implicó en atrasos.

Las movilizaciones de las comunidades originarias se fortalecieron en ese espacio de tiempo, realizando inúmeras manifestaciones y pedidos al gobierno para la suspensión de la obra, en especial para el segundo tramo de la carretera que atravesaría el territorio indígena. El ápice de los conflictos fue en 2011, cuando los pobladores del Tipnis caminaron por 65 días contra el proyecto de construcción de la carretera San Ignacio de Mojos-Villa Tunari. 
Campos Neutrais - Revista Latino-Americana de Relações Internacionais Vol. 1, $\mathrm{N}^{\mathrm{O}}$ 2, p. 40-52, Maio - Agosto de 2019

Partieron de Trinidad (Beni) con dirección a La Paz y fueron sorprendidos con una brutal represión en Chaparina ${ }^{8}$. Con la llegada de la columna a la sede de Gobierno se logró que el presidente Evo Morales promulgase la Ley 180, que instituyó la intangibilidad al Territorio Indígena y suspendió el proyecto para el camino.

Un año después el tema se recoloca a través de una Consulta Previa que se lleva a cabo en 2013 de la cual resulta una supuesta "aceptación" de los pueblos originarios a la construcción de la carretera ${ }^{9}$. No obstante, el préstamo concedido por el BNDS en el marco de los acuerdos del IIRSA ya no estaba de pie y habría que aguardar otros recursos para su implementación.

En 2017 un nuevo impulso del gobierno central presenta a la cámara de diputados un proyecto de ley de "Protección, desarrollo integral y sustentable del Territorio Indígena y Parque Nacional Isiboro Sécure”, que contempla apertura de caminos vecinales, carreteras, sistemas de navegación pluvial, aérea y otras obras de infraestructura. Abriendo un nuevo ciclo de embates con los indígenas que se declaran en situación de emergencia.

Razones plausibles existen de ambos lados del conflicto: si por un lado abrir la carretera y otras vías de comunicación en el TIPNIS es una forma de integrar el país y sentar la presencia del Estado en la Amazonia boliviana, evitando su control y explotación por parte de grupos mafiosos, narcotraficantes, ganaderos, madereros; también es real que la carretera causará un impacto negativo a la preservación del hábitat, costumbres y formas de vida de los grupos indígenas originarios. Una de las dimensiones presentes en el conflicto es el apoyo explícito del gobierno a los colonos del Chapare que defienden el trazado y la construcción de la carretera. Considerando que la principal fuente de recursos de esa población es la hoja de coca, cuyo cultivo, consumo y comercialización es altamente polémico y de por sí conflictivo nacional e internacionalmente, a seguir intentamos desvendar algunos aspectos para facilitar su mejor comprensión.

\section{La producción de coca: entre práctica sagrada y criminal}

La hoja de coca, o "planta sagrada" es consumida por la población indígena del altiplano desde mucho antes de la colonización hispánica. Es parte de varios rituales sagrados del Imperio Inkaico y hay, inclusive, registros anteriores de su consumo medicinal y ritual.

8 Conocido como "masacre de Chaparina" fue la represión policial más brutal contra población civil desarmada, hombres, mujeres y niños, sorprendidos por las fuerzas armadas en uno de los acampamentos de la marcha pacífica que se dirigía a La Paz para expresar su descontentamiento con la construcción de la carretera.

$9 \quad$ Algunos movimientos sociales y sindicales contestaron la forma como se procesó la Consulta. 
Campos Neutrais - Revista Latino-Americana de Relações Internacionais Vol. 1, $\mathrm{N}^{\mathrm{O}}$ 2, p. 40-52, Maio - Agosto de 2019

Después de la colonización hispánica y del sometimiento de las poblaciones de América, los indígenas pasaron a utilizarla como estimulante para enfrentar las condiciones inhumanas de trabajo forzado. Era una planta encontrada en la naturaleza, cuidada y reverenciada por sus propiedades curativas y por su carácter sagrado.

La región selvática del Chapare, fue colonizada por campesinos indígenas estimulados por el gobierno en la segunda mitad del siglo XX, más específicamente durante el gobierno dictatorial posterior a la revolución de $1952^{10}$. Hasta entonces la coca no era cultivada en gran escala, ni ocupaba un lugar de destaque en la economía del país. No obstante, después de la crisis mundial de los años 1970, Bolivia se ve arrastrada a una grave crisis económica, cierre de minas que ocupaban parte de la mano de obra rural y fuerte migración campo ciudad. Es en ese contexto que la plantación de coca para exportación, principalmente a los EUA, se convierte en el principal producto de exportación y muchos campesinos se dedicarán al monocultivo de la coca que pasó a ser el principal producto de exportación boliviana durante los años 1971 a 1982, último periodo de los gobiernos dictatoriales.

Entre la hoja de coca y la cocaína hay un proceso de industrialización química para la extracción del producto alucinógeno y ese proceso no es realizado por los productores bolivianos y sí por los importadores, inclusive afamados laboratorios farmacéuticos que utilizan esta materia prima para fines medicinales. Mismo reconociendo este hecho, los Estados Unidos, principales compradores y consumidores de cocaína para fines recreativos a nivel mundial, forzaron la creación y financiaron una estructura militar de control y erradicación de los cultivos ilegales. Posteriormente el gobierno boliviano establece una ley (ley 1008 de 1988) que reconoce el uso tradicional de la coca y demarca la diferencia de su uso ilegal, así como establece áreas de cultivo permitido y áreas de cultivo restringido.

Una de las áreas de erradicación del cultivo fue el Chapare, acompañado por propuestas alternativas de desarrollo local e indemnizaciones, pero también de criminalización y violencias contra los productores. Lo cierto es que el cultivo de coca en la región se vio estimulado por el alza de precios del producto y por la escaza participación de otros productos alternativos para el mercado. Las tentativas de erradicación de los posteriores

10 La Revolución boliviana de 1952 fue resultado de un proceso histórico de negación de las clases populares por parte de las oligarquías que condujeron el Estado y las riquezas de Bolivia. La Revolución que en un primer momento era vista como la restitución de la institucionalidad política y la aceptación del resultado electoral de 1951, se transformó en un movimiento popular de masas que derrocó el Estado oligárquico, a pesar de que los sectores políticos más radicales fueron sometidos por la organización y dinámica de un Estado moderno colonial, se sentaron las bases para la organización sindical y la ampliación de los espacios de decisión política que pasaron a incluir sectores hasta entonces silenciados. 
Campos Neutrais - Revista Latino-Americana de Relações Internacionais

Vol. 1, No 2, p. 40-52, Maio - Agosto de 2019

gobiernos ${ }^{11}$ generaron reacciones por parte de los productores cocaleros, que demostraron gran capacidad organizativa, conquistando espacios de destaque en los principales sindicatos nacionales y movilizando sectores importantes de la población.

En este movimiento reivindicativo se construye la figura del líder Evo Morales, en un primer momento como una referencia sindical y posteriormente en la formación del MAS como partido político que irá representar el movimiento cocalero en las disputas electorales a partir de 1995, conquistando cargos a nivel municipal y de representación nacional, hasta ganar las elecciones presidenciales de 2005.

La recuperación de este proceso es importante para entender que la base electoral del actual gobierno boliviano es indígena, campesina y cocalera, lo que significa compromisos políticos que acompañan todo el periodo de los gobiernos (2006 y 2009) de Evo Morales hasta el presente.

\section{A modo de conclusión}

La carretera por el TIPNIS se ha convertido en símbolo alrededor del cual gravita un complejo entramado de sujetos, asuntos e intereses que disputan el territorio con valoración divergente respecto de los recursos naturales, lo que significa diferentes concepciones al respecto de la naturaleza que se sustentan en visiones antagónicas sobre desarrollo.

Están presentes en este conflicto cuestiones eminentemente ambientales abordadas desde ópticas muy diversas y complejas. Como mencionamos en este trabajo, derechos indígenas consagrados en convenios internacionales y en la Constitución Política del Estado boliviano; una dimensión político partidaria presente en intereses de los grupos de apoyo y de oposición al gobierno; una dimensión económica, que mismo imbricada en la anterior, tiene sus propias especificidades e inclusive confronta grupos indígenas de diferentes etnias.

Como apunta Svampa, las ambivalencias y contradicciones aparecen en las posiciones adoptadas por el presidente boliviano, que al mismo tiempo que defiende una dimensión preservacionista y de reivindicación eco-territorial "hacia afuera"; conduce internamente su práctica de gobierno por una lógica "nacional productivista que refleja la consolidación del paradigma extractivista" (Svampa, 2011: 424). Al violar la ley de intangibilidad del TIPNIS, se somete el territorio a las exigencias de la acumulación ampliada del capital que se expresa a través de la reducción de los recursos naturales a materias primas para las industrias

11 En 1998, el gobierno de Hugo Bánzer, mediante el Plan Dignidad, se propuso reducir la producción de coca al nivel cero en cinco años. (Makara, 2013) 
Campos Neutrais - Revista Latino-Americana de Relações Internacionais Vol. 1, $\mathrm{N}^{\mathrm{O}}$ 2, p. 40-52, Maio - Agosto de 2019

extractivas de hidrocarburos, minerales, madereras en detrimento de la protección del ecosistema y de las comunidades indígenas de la amazona.

Parece que el Estado colonial, republicano y neoliberal que se intenta suprimir con la nueva Constitución boliviana, aún no abandona las prácticas de poder entre grupos de interés que continúan oscilando entre una retórica del Buen Vivir que alcance a todas las naciones que constituyen el país, su población y riquezas naturales, y la funcionalidad del inmediatismo del desarrollo nacional colonial que retoma la explotación desenfrenada de ecosistemas con finalidades de acumulación de riquezas en todo el mundo.

\section{Bibliografía}

ALANOCA Paco, Jesús Reynaldo (2017): 7 claves para entender el nuevo conflicto del Tipnis, Santa Cruz de la Sierrra, www.eldeber.com.bo/06/08/2017 (acceso en 23/5/18)

ECUADOR, Cáritas (2018): El secreto del proyecto carretera TIPNIS, Quito, agosto 2, 2017, www. repam. Org (acceso en 12/1/18)

COLOMBRO, Adolfo (org.) (1989): 1492 - 1992: A los 500 años del choque entre dos mundos, balance y perspectivas; Buenos Aires, Ediciones del Sol.

FUSER, Igor (2018): Os 10 eixos do IIRSA, Le Monde Diplomatique, 19/05/2018.

MAKARA, Gaya. (2013) Volveré y seré millones: el movimiento indígena boliviano, En: Natividad Gutiérrez Chong (coordinadora) Etnicidad y Conflicto En Las Américas, Volumen II: Violencia y Activismo Político, México, Universidad Nacional Autónoma de México - Instituto de Investigaciones Sociales.

MAMANI Condori, Carlos (2013): EI Qullasuyu en el camino de su reconstitución.Visión política y marco filosóficodel CONAMAQ, La Paz, Bolivia.

MARIÁTEGUI, José Carlos (2004): Siete ensayos de interpretación de la realidad peruana, $1^{\text {a }}$ edición, Buenos Aires, Gorla.

OIT (2014): Convenio 169; Lima: OIT/Oficina Regional para América Latina y el Caribe disponible en: http://www.ilo.org (acceso en 27/12/2016)

PRADA Alcoreza, Raúl (2017): La farsa del comediante. 29/08/2017.

https://voluntaddepotencia.wordpress.com (acceso en 09/10/2017)

QUIJANO, Aníbal (1992): "Colonialidad y Modernidad-racionalidad". In: BONILLO, Heraclio (comp). Los conquistados. Bogotá: Tercer Mundo Ediciones; FLACSO.

QUIJANO, A y Wallerstein, I. (1992): La americanidad como concepto, o América en el moderno sistema mundial, En: Revista Internacional de Ciencias Sociales, UNESCO, Catalunya.

STEFANONI, Pablo (2017): Algunas claves del conflicto del TIPNIS, Rebelión, 02-10- 
Campos Neutrais - Revista Latino-Americana de Relações Internacionais

Vol. 1, No 2, p. 40-52, Maio - Agosto de 2019

2011 (acceso en 15/3/18)

SYAMPA, Maristella (2011): Modelo de desarrollo y cuestión ambiental en América Latina: categorías y escenarios en disputa, En: Wanderley, Fernanda (coord.) El desarrollo en cuestión, reflexiones desde América Latina, La Paz, Plural Editores, UMSA/OXFAM.

SYAMPA, Maristella (2013): Bolivia, modelo 2013, en perspectiva, www.sinpermiso.info (acceso en 23/4/2018) 